\title{
Um olhar para os saberes docentes que estruturam a prática pedagógica do professor universitário
}

\author{
Knapik, Mário José ${ }^{1}$ \\ Behrens, Marilda Aparecida² \\ Prigol, Edna Liz ${ }^{3}$
}

\section{Resumo}

Esta pesquisa de cunho qualitativo, do tipo estudo de caso, com procedimentos via netnografia, permitiu identificar as contribuições registradas por professores formadores da área de educação. Partimos do seguinte problema de pesquisa: quais os tipos de saberes docentes estruturam a prática pedagógica dos professores e como se caracterizam as bases ontológicas e epistemológicas que sustentam esses saberes? Objetivou-se identificar os tipos de saberes docentes implícitos nos depoimentos dos professores investigados, relacionados com as bases científicas e os construtos epistemológicos que fundamentam a sua docência. A pesquisa se desenvolveu em dois momentos, com 16 participações envolvendo mestrandos, doutorandos e pós-doutorandos do grupo de pesquisa. Primeiramente, realizou-se estudo dos saberes docentes propostos por Tardif $(1991,2002)$, Gauthier (1998) e Pimenta (1999), que geraram as sínteses que alicerçaram a elabo ração do roteiro da entrevista e a definição das categorias. A segunda etapa consistiu na aplicação da entrevista semiestruturada, com 20 professores que atuam na docência da formação inicial e/ou continuada. Os resultados revelam a presença de conhecimentos pedagógicos, epistemológicos, ontológicos e filosóficos que fundamentam e dão sentido às atividades docentes.

Palavras-chave: Professor do ensino superior; Pensamento complexo; Prática pedagógica; Saber docente.

\section{A look at the teaching knowledge that structures the teaching practice of the university teachers}

\begin{abstract}
This qualitative research, of the case study type, with procedures by netnography, made it possible to identify the contributions registered by educating teachers in the area of education. We start from the following research problem: what types of teaching knowledge structure the pedagogical practice of teachers and how are the ontological and epistemological bases that support this knowledge characterized? The objective was to identify the types of teaching knowledge implicit in the testimonies of the investigated teachers, related to the scientific bases and the epistemological constructs that underlie their teaching. The research was carried out in two stages, with 16 participations involving master's, doctoral and post-doctoral students from the research group. First, a study of the teaching knowledge proposed by Tardif $(1991,2002)$, Gauthier (1998) and Pimenta (1999) was carried out, which generated the syntheses that supported the elaboration of the interview script and the definition of the categories. The second stage consisted of the application of the semi-structured interview, with 20 teachers who work in the teaching of initial and / or continuing education. The results reveal the presence of pedagogical, epistemological, ontological and philosophical knowledge that underlie and give meaning to teaching activities.

Keywords: Higher education professor; Complex thinking; Pedagogical practice; Teacher Knowledge.
\end{abstract}

\footnotetext{
${ }^{1}$ FAE Centro Universitário, Curitiba, Paraná. mario.knapik@bomjesus.br

2 Pontifícia Universidade Católica do Paraná, Curitiba. marildaab@gmail.com

${ }^{3}$ Pontifícia Universidade Católica do Paraná, Curitiba. prigoledna@gmail.com
} 


\section{Introdução}

O professor universitário da contemporaneidade necessita, além do domínio de conhecimentos específicos de sua área e de saber ensiná-los, compreender o significado e a possibilidade de fazer com que os acadêmicos se apropriem de conteúdos e possam utilizá-los para se transformar em cidadãos do mundo, aptos a enfrentar os desafios impostos pela sociedade.

Persiste um saber docente decorrente da ciência clássica, em que prevalece o pensamento assentado nas visões reducionistas, da separatividade e da homogeneização, que influenciam as questões epistemológicas e as teorias de aprendizagem, as quais fundamentam as concepções educacionais e, consequentemente, a orientação da prática pedagógica. 0 modelo cartesiano newtoniano continua influenciando a educação, explicando, assim, a forma como os indivíduos reproduzem o conhecimento e sua interferência na maneira de ser, viver, conviver, aprender e fazer.

Dessa forma, faz-se necessário romper as fronteiras dos conhecimentos disciplinares enclausurados no espaço acadêmico, voltando-se para uma racionalidade aberta, dialógica, intuitiva e global, que reconheça a necessidade de um conjunto de princípios teóricos e epistemológicos que auxiliem na busca de novos caminhos e na condução de uma docência que religue os diversos saberes em diferentes dimensões da vida e perceba a complexidade das relações existentes entre as partes e o todo.

Estudos realizados nessas áreas (TARDIF, 1991, 2002; GAUTHIER et al., 1998; PIMENTA, 1999; ZEICHNER, 1983; PINEAU, 1983; NOVOA E FINGER, 1998), mostram que o docente edifica sua docência pela ingerência de suas qualidades pessoais, pelo conhecimento teórico, pela sua referência epistemológica de educação, pela sua trajetória de vida pessoal e profissional, com base nos valores, crenças e atitudes, condições de trabalho que a instituição de ensino lhe oferece, entre outros aspectos. Cabe ainda salientar que a construção dos saberes docentes é um percurso não linear, ao longo do tempo e em diversos contextos, permitindo identificar o docente como um sujeito histórico e que se faz professor universitário, tendo sua prática pedagógica estruturada a partir de suas reflexões.

Diante desse contexto, surge a seguinte questão: quais os tipos de saberes docentes 
estruturam a prática pedagógica dos professores e como se caracterizam as bases ontológicas e epistemológicas que sustentam esses saberes? A pesquisa teve como objetivo identificar os tipos de saberes docentes implícitos nos depoimentos dos professores investigados, relacionados com as bases científicas e os construtos epistemológicos que fundamentam a sua docência.

O estudo originou-se da pesquisa aprovada pelo Conselho Nacional de Desenvolvimento Científico e Tecnológico (CNPq), intitulada "Paradigma da complexidade e transdisciplinaridade como pilares epistemológicos para geração de construtos, saberes e práticas na formação pedagógica dos professores", vinculada ao grupo de pesquisa Paradigmas Educacionais e Formação de Professores - PEFOP, composto atualmente por 16 mestrandos, doutorandos e pós-doutorandos do programa de pós-graduação de uma Universidade privada do sul do Brasil.

O processo investigativo envolveu discussões de situações reais junto aos pesquisadores no grupo de pesquisa, para que, por meio de entrevistas com os docentes participantes da pesquisa, pudesse compreender o contexto em que os saberes ocorrem, possibilitando coletar dados a partir do registro da concepção dos envolvidos.

Esta pesquisa foi desenvolvida em duas etapas, sendo a primeira o estudo dos saberes docentes, propostos por Tardif (1991, 2002), Gauthier et all (1998) e Pimenta (1999), gerando as sínteses que alicerçaram a elaboração do roteiro da entrevista e a definição das categorias. A segunda etapa consistiu em detectar nas contribuições dos participantes sobre a visão epistemológica dos saberes docentes presentes nas entrevistas.

Muitos são os desafios, perspectivas, inquietações e indagações sobre os saberes docentes do professor universitário, na busca de alternativas para a superação das incoerências presentes na atuação em sala de aula, permeadas por um fazer pedagógico instrumental e mecânico que conduz à alienação profissional assentada em verdades absolutas.

\section{Concepções e tipologias dos saberes docentes}

Para falar sobre os saberes docentes e entender quais são, como estão estruturados, qual é a influência deles no processo de ensino-aprendizagem, quem os define, quais são sua natureza, suas características e sua ingerência na identidade docente, é necessário dialogar com 
alguns autores que pesquisaram a temática. Trata-se de compreender que as ideias revisitadas devem ser vistas como complementares, mas também identificar seus antagonismos, com a finalidade de substituir a lógica linear e unidirecional, possibilitando uma nova percepção e, consequentemente, um novo olhar para os saberes e o fazer docente, reforçando a ideia do global, em vez de apenas local, ou seja, a visão sistêmica em oposição ao fracionamento, que permite perceber o professor como um ser humano integral, constituído de mente, corpo, razão, emoção e intuição.

Para a construção de uma tessitura sobre os saberes docentes, optou-se por dialogar com Tardif (1991, 2002), Gauthier (1998) e Pimenta (1999), com a finalidade de apreender como definem os saberes docentes numa perspectiva conceitual e tipológica.

Para falar sobre o saber dos professores, Tardif (2002) busca navegar em uma visão multidimensional, uma vez que o saber não é algo solto, mas, sim, contextualizado. Para ele, o saber dos docentes "[...] está relacionado com a pessoa e a identidade deles, com a sua experiência de vida e com sua história profissional, com suas relações com os alunos em sala de aula e com os outros atores escolares na escola, etc." (TARDIF, 2002, p. 11).

A tessitura realizada nesta pesquisa, com base em Tardif (2002), considerou alguns fios condutores, isto é, ideias que orientam e alimentam a construção de uma teoria sobre os saberes docentes: saber e trabalho; diversidade do saber; temporalidade do saber; experiência de trabalho como fundamento do saber; saberes humanos a respeito de saberes humanos; saberes e formação profissional. A compreensão desses fios condutores esclarece que o saber docente é plural e heterogêneo. Dessa forma, a função do professor supera a transmissão de conhecimentos por meio da linearidade e racionalização, desvinculados do contexto no qual estão inseridos. Nessa perspectiva, Tardif (2002) esclarece que a prática docente se compõe de diferentes saberes, os quais servem de base para o processo de ensinar, que mobiliza as noções existenciais, sociais e pragmáticas. São eles: saberes das disciplinas; saberes curriculares; saberes da experiência; e saberes da formação profissional.

Os saberes da formação profissional (das ciências da educação e da ideologia pedagógica) são conhecimentos gerais e pedagógicos relacionados às técnicas e métodos de ensino (saberfazer) adquiridos ao longo da formação inicial e continuada e que se transformam em saberes que se destinam à formação científica ou erudita dos docentes. 
Os saberes disciplinares relacionados aos diferentes campos do conhecimento, produzidos e disseminados ao longo da história, são adquiridos pelos professores durante o estudo realizado na universidade, por meio de várias disciplinas. Esses "[...] saberes das disciplinas emergem da tradição e dos grupos sociais produtores de saberes" (TARDIF, 2002, p. 38) e são incorporados à prática docente.

Os saberes curriculares são os programas escolares, com objetivos, métodos e conteúdo, que precisam ser conhecidos pelos professores para ser trabalhados com os alunos. Finalmente, os saberes experienciais "[...] incorporam-se à experiência individual e coletiva sob a forma de habitus e de habilidades, de saber-fazer e de saber ser" (TARDIF, 2002, p. 38). São adquiridos durante o exercício da docência e produzidos pelas interações com seus pares e com os alunos, na instituição de ensino.

Outra contribuição que envolve os saberes profissionais docentes é a de Gauthier et al. (1998), que por meio de análises de pesquisas norte-americanas, constrói o que denomina knowledge base (base de conhecimento), referente a um conjunto de conhecimentos, habilidades e atitudes que o professor precisa para a sua prática pedagógica. Os estudos realizados permitiram identificar um grande desafio para a profissionalização docente, com a necessidade de superar os limites impostos pelo pensamento reducionista e simplificador que acabou gerando o ofício sem saberes e saberes sem ofício. Para essa problemática, propõe-se um ofício feito de saberes, compostos por: disciplinares; curriculares; experienciais; das ciências da educação; da tradição pedagógica; e da ação pedagógica.

Entende-se por ofício sem saberes o conjunto de habilidades necessárias à docência, que, de acordo com o senso comum, podem ser resumidas em: conhecer o conteúdo da disciplina que o professor irá ministrar; ter o dom natural de saber transmitir conhecimentos usando o bom senso e a intuição; e, por fim, ter experiência com a docência.

A construção de saberes sem ofício, segundo Gauthier et al. (1998) são conhecimentos produzidos nos centros acadêmicos, originalmente das ciências da educação. Numa visão conservadora, criou-se uma pedagogia científica, fundamentada nos construtos da racionalidade técnica e reducionista, com métodos e demais princípios pedagógicos para o desenvolvimento eficaz do saber-ensinar. Contudo, a docência tem uma incumbência mais ampla do que a proposição reducionista de executar técnicas que são importantes, mas não dão conta de 
responder aos problemas da realidade circundante, ou seja, são insuficientes para a formação dos alunos cidadãos, que envolve saberes ligados a uma dimensão epistemológica complexa que entrelaça a visão educacional, social e política, entre outras.

Para encontrar uma solução que supere essa visão reducionista, Gauthier et al. (1998) indica os saberes necessários para o professor atuar em sala de aula. Propõe a mobilização de vários saberes que auxiliem a dialogar com as emergências para responder às exigências das situações concretas de ensino, superando o ofício sem saberes e saberes sem ofício, para a proposta do ofício feito de saberes composta de uma classificação de seis saberes específicos para os docentes.

O saber disciplinar remete ao conhecimento do conteúdo de uma disciplina que precisa ser compreendido pelo professor, para que possa transferir didaticamente os saberes elaborados pelos pesquisadores e cientistas para os alunos. Outro saber que o docente precisa dominar é o saber curricular, pois necessita entender que uma disciplina, para ser trabalhada em sala de aula, independentemente do nível e modalidade de ensino, deve ser transformada em um programa, isto é, a conversão dos saberes produzidos pela ciência num corpus que comporá o currículo escolar.

A profissão docente exige desse profissional conhecimentos que vão além de saberes específicos de uma disciplina, área de conhecimento ou prática pedagógica, incluindo saberes específicos da instituição de ensino, como, por exemplo, aqueles relativos à sua organização, sua estrutura, seu funcionamento, seu regimento, sua proposta pedagógica, enfim, conhecimentos concernentes à gestão escolar e a respeito da própria profissão docente, o que é denominado por Gauthier et al. (1998) saber das ciências da educação.

O professor, antes de ser um profissional da educação, passou pelos bancos escolares, da infância até a sua formação profissional, e neles muitos aprendizados e vivências ocorreram, possibilitando-Ihe ter preconcepções do que é ser professor. Nesse contexto, foi estruturado o saber denominado tradição pedagógica, que corresponde ao conhecimento relativo ao saber ministrar uma aula, adaptado e modificado pelo saber experiencial.

Outro saber estruturado por Gauthier et al. (1998) é o saber da experiência, pois, no dia a dia, o professor enfrenta desafios, como também propõe soluções; são autorregulações que ocorrem de acordo com a necessidade. Conforme o professor vivencia sua docência, faz 
reflexões e promove julgamentos individuais, construindo, ao longo do tempo, uma espécie de jurisprudência.

Já o saber da ação pedagógica corresponde às decisões do professor em sala de aula, fundamentadas nos saberes anteriores. Trata-se da construção de uma teoria da pedagogia validada pelas ações empíricas realizadas em sala de aula uma "[...] simples aplicação dos saberes para resolver a situação, precisa deliberar, julgar e decidir com relação à ação a ser adotada, ao gesto a ser feito ou à palavra a ser pronunciada antes, durante e após o ato pedagógico" (GAUTHIER et al., 1998, p. 31).

Outro estudo eleito pelo grupo de pesquisa sobre saberes docentes foi a proposta de Pimenta (1999), que tem como foco a identidade da profissão do professor para chegar à questão dos saberes docentes. Para falar sobre estes, busca expor a respeito dos processos de desenvolvimento do professor na formação inicial, especificamente nos cursos de licenciatura. Para a autora, o saber e o saber-fazer do professor se estruturam na tríade: saberes dos conhecimentos, saberes pedagógicos e saberes da experiência.

Os saberes da experiência podem ser identificados pela história de vida, que permite verificar o que o professor já conhece sobre sua profissão por meio de suas experiências como discente, vivências que possibilitam se lembrar de aulas, ou seja, professores que de algum modo influenciaram ou influenciam sua docência.

Para explicar o saber corresponde ao conhecimento, Pimenta (1999) busca em Morin (1993) fundamentos, informando que o significado de conhecimento deve superar a visão de que são aqueles relacionados apenas ao domínio de conteúdos da área em que o professor irá atuar, pois "[...] conhecer significa estar consciente do poder de conhecimento para a produção da vida material, social e existencial da humanidade" (PIMENTA, 1999, p. 22).

Por fim, os saberes pedagógicos, que incitam ir além da didática instrumental, precisam ser constituídos por meio de exame crítico e intencional da ação docente, em especial, a partir de sua prática social de ensinar, articulada à teoria pedagógica, uma vez que, “[...] frequentando os cursos de formação, os futuros professores poderão adquirir saberes sobre a educação e sobre a pedagogia, mas não estarão aptos a falar sobre em saberes pedagógicos" (PIMENTA, 1999, p. 26). 


\title{
Desenho metodológico da pesquisa
}

A pesquisa é de cunho qualitativo, do tipo estudo de caso, o que permitiu identificar contribuições sobre os saberes na docência junto aos professores que atuam na formação inicial e continuada na área da educação superior. Buscou-se levantar os saberes docentes para que pudessem ser compreendidos no contexto em que ocorrem, possibilitando coletar dados a partir da concepção dos envolvidos, ou seja, por meio de entrevista, assim foi possível registrar as falas dos professores universitários sobre a temática dos saberes docentes.

A opção pela abordagem qualitativa, de acordo com Flick (2004, p. 27), atende ao encaminhamento do estudo, pois

\begin{abstract}
a pesquisa qualitativa trabalha, sobretudo, com textos. Métodos para a coleta de informações - como entrevistas e observações - produzem dados que são transformados em textos por gravações e transcrição. Os métodos de interpretação partem desses textos. Caminhos diferentes conduzem aos textos do centro da pesquisa e também se afastam destes. De forma bem resumida, o processo de pesquisa qualitativa pode ser representado como uma trajetória que parte da teoria em direção ao texto, e outra do texto de volta para a teoria. A interseção dessas duas trajetórias é a coleta de dados verbais ou visuais e a interpretação destes em um plano de pesquisa específico.
\end{abstract}

Entende-se estudo de caso como uma metodologia de pesquisa educacional para descrever e analisar uma unidade social, que "se desenvolve numa situação natural, é rico em dados descritivos, tem um plano aberto e flexível e focaliza a realidade de forma complexa e contextualizada" (LUDKE; ANDRE, 2013, p. 18). Segundo André (2013), o estudo de caso em uma abordagem qualitativa utiliza o contexto das situações escolares, empregando técnicas de observação e entrevistas para descrever as experiências escolares no cotidiano.

Para a produção dos dados foi delineado o universo da pesquisa com professores universitários que ministrassem aula na educação superior tanto da formação inicial como continuada. Cada componente do grupo de pesquisa selecionou um professor de sua instituição para fazer parte da amostragem da pesquisa, totalizando 20 professores, conforme pode ser visualizado no

Quadro 1. 
Quadro 1- Caracterização dos professores participantes da entrevista

\begin{tabular}{|l|l|l|l|l|}
\hline Participante & Curso de Formação inicial & $\begin{array}{l}\text { Federal ou } \\
\text { Privada }\end{array}$ & Mestrado & Doutorado \\
\hline P1 & Pedagogia & Privada & Sim & Sim \\
\hline P2 & Matemática & Federal & Sim & Em andamento \\
\hline P3 & Pedagogia & Privada & Sim & Não \\
\hline P4 & Pedagogia e Ciências Sociais & Pública & Sim & Não \\
\hline P5 & Pedagogia & Pública & Sim & Sim \\
\hline P6 & Pedagogia & Privada & Sim & Sim \\
\hline P7 & Pedagogia & Privada & Sim & Sim \\
\hline P8 & Pedagogia & Federal & Sim & Sim \\
\hline P9 & Biblioteconomia & Privada & Sim & Sim \\
\hline P10 & Filosofia & Privada & Sim & Sim \\
\hline P11 & Ciências Biológicas & Pública & Sim & Em andamento \\
\hline P12 & Pedagogia & Publica & Sim & Sim \\
\hline P13 & Pedagogia & Privada & Sim & Em andamento \\
\hline P14 & Pedagogia & Privada & Sim & Em andamento \\
\hline P15 & Pedagogia & Estadual & Sim & Em andamento \\
\hline P16 & Filosofia & Privada & Sim & Sim \\
\hline P17 & Pedagogia e Desenho Industrial & Privada & Sim & Não \\
\hline P18 & Pedagogia & UFPR & Sim & Sim \\
\hline P19 & Pedagogia & UFPR & Sim & Sim \\
\hline P20 & Matemática & Privada & Sim & Em andamento \\
\hline & & & \\
\hline
\end{tabular}

Fonte: os autores, 2020

Tomou-se para investigação o seguinte problema: a seguinte questão: quais os tipos de saberes docentes estruturam a prática pedagógica dos professores e como se caracterizam as bases ontológicas e epistemológicas que sustentam esses saberes? Para levantar possíveis respostas à indagação, foi utilizada como instrumento de coleta de dados a entrevista focalizada, que tem como objetivo um tema bem específico, possibilitando ao entrevistado falar espontaneamente sobre o assunto, porém sem perder o foco do tema.

Esta pesquisa foi desenvolvida em duas etapas, sendo a primeira o estudo dos saberes docentes, por meio da construção de sínteses pelos participantes do grupo de pesquisa PEFOP que subsidiaram a elaboração do roteiro da entrevista e a definição das categorias e suas conceituações para análise. Elegeram-se para leitura, discussão e análise os autores Tardif (1991, 2002), Gauthier et al. (1998) e Pimenta (1999), que se destacam por suas contribuições na temática sobre saberes docentes. O Quadro 2 apresenta a categorização e conceituação dos 
saberes docentes elaboradas pelo grupo de pesquisa.

Quadro 2 - Categorias e conceituação

\begin{tabular}{|l|l|l|}
\hline Dimensão & Categoria & Conceito geral \\
\hline Pedagógica & Metodológico-didático & $\begin{array}{l}\text { São saberes relacionados com a prática educativa, orientando o } \\
\text { saber ensinar. }\end{array}$ \\
\cline { 2 - 3 } & Curricular & $\begin{array}{l}\text { Saber relacionado com o conhecimento sobre o currículo e o } \\
\text { programa escolar (objetivos, conteúdos, métodos, avaliação). }\end{array}$ \\
\hline Ontológica & Experiencial & $\begin{array}{l}\text { São saberes originados da prática cotidiana da profissão e } \\
\text { refletidos continuamente pelo docente. }\end{array}$ \\
\hline & Conhecimento & $\begin{array}{l}\text { São saberes adquiridos na formação inicial, continuada e em } \\
\text { serviço que auxiliam o professor na sua profissão e a ter clareza } \\
\text { sobre a importância do conhecimento no processo educativo. }\end{array}$ \\
\hline
\end{tabular}

Fonte: os autores, com base em Tardif (1991, 2002), Gauthier et al. (1998) e Pimenta (1999).

Num segundo momento, cada membro do grupo PEFOP realizou uma ou mais entrevistas, totalizando 20 participantes professores universitários que atuam na docência da formação inicial e/ou continuada, ou seja, trabalham na formação de formadores. Nesta fase da pesquisa para a produção de dados, foi aplicada entrevista semiestruturada, compreendida como uma conversa direcionada, que possibilita ao pesquisador ser mais detalhista, podendo se aprofundar de modo a obter mais esclarecimentos sobre alguns tópicos essenciais. Os participantes assinaram termo de livre consentimento e foram denominados P1 a P20, para salvaguardar o anonimato. A entrevista foi estruturada em torno das palavras aglutinadoras "complexidade", "transformação" e "saberes docentes na formação de professores", organizadas em três blocos. Para esse artigo, elegeu-se os questionamentos do bloco 1 que buscou identificar as bases científicas e os construtos que estruturam a prática pedagógica dos professores entrevistados.

Quadro 3 - Roteiro da entrevista

Bloco 1 - Conhecimentos pedagógicos, epistemológicos e ontológicos que fundamentam e dão sentido à sua atividade docente.

Contextualização: Para falar sobre os saberes docentes e entender quais são, como estão estruturados, qual é a influência na docência, quais são sua natureza, suas características, sua ingerência na identidade docente, faz-se necessário entender como esses conhecimentos foram tecidos, isto é, identificar qual foi a trama de aprendizados ocorridos durante o desenvolvimento pessoal e profissional do professor. A profissão docente exige conhecimentos que vão além de saberes específicos de uma disciplina, área de conhecimento ou prática pedagógica, incluindo o domínio de saberes e saber-fazer que sustentam sua prática pedagógica.

Questionamento: Quais bases científicas/construtos fundamentam seus saberes relacionados à prática

Periódico Horizontes - USF - Itatiba, SP - Brasil - e020027 


\section{HSE}

pedagógica? Fale sobre eles.

Fonte: elaborado pelos pesquisadores do grupo de pesquisa, 2019

A pesquisa acolheu procedimentos via netnografia, como recurso digital de investigação, isto é, utilizou-se de processos que permitiram interações e comunicações mediadas pelo computador com auxílio da internet (KOZINETS, 2014). As entrevistas foram transcritas e disponibilizadas para todos os pesquisadores envolvidos do grupo PEFOP, no Google Docs. Esses registros foram utilizados em momentos de discussões presenciais e on-line para o estudo e a construção dos instrumentos de levantamento de dados.

\section{Contribuições dos professores universitários que atuam na formação inicial e continuada na área da educação}

Com foco no objetivo desta pesquisa, buscou-se identificar os tipos de saberes docentes implícitos nos depoimentos dos professores investigados relacionados com as bases científicas e os construtos pedagógicos, ontológicos e epistemológicos que fundamentam a sua docência. Para tanto, foram realizadas as entrevistas, das quais se extraíram as falas dos 20 participantes a partir da indagação: quais bases científicas/construtos fundamentam seus saberes relacionados à prática pedagógica? Tal indagação envolve o bloco 1, apresentado no Quadro 2. As respostas foram lidas e analisadas de maneira que cada pesquisador do grupo pudesse identificar nas contribuições dos docentes nas categorias (Quadro 1) definidas após estudo de Tardif (1991, 2002), Gauthier et al. (1998) e Pimenta (1999).

Para a dimensão pedagógica, consideraram-se os saberes curriculares e metodológicodidáticos, estes entendidos como saberes que estão relacionados com a prática educativa, orientando o saber ensinar, ou seja, nas palavras de Pimenta et al. (2013, p. 150), a “[...] construção de conhecimentos que possibilitem a mediação entre o que é preciso ensinar e o que é necessário aprender; entre o saber estruturado nas disciplinas e o saber ensinável mediante as circunstâncias e os momentos". A partir dessa compreensão, encontraram-se alguns relatos que se aproximam da ideia relacionada com o saber-fazer, com a prática pedagógica, conforme se pode ler a seguir: 
A sala de aula poderia ser uma local para absorver e estimular questionamentos e, por isso, é necessário dialogar com o conteúdo das realidades sociais. Portanto, parece ser adequado o cuidado para proporcionar os meios adequados ao processo, como a ergonomia do ambiente da sala de aula, a didática que possibilita o diálogo entre disciplinas, o diálogo entre as culturas (P1).

Por exemplo, a concepção de sala de aula invertida é algo que é difícil para o professor fazer, assim como é difícil para o nosso aluno, mesmo bastante jovem, mesmo, como que a gente fala, ele não é um imigrante digital, é um nativo digital, e ele é resistente a essa metodologia (P7).

Se fala hoje em educação por pares, sendo que isso já era trabalhado na escola montessoriana, a possibilidade de interagir e fazer trocas com outros colegas de classe, de diferentes níveis de conhecimento, com habilidades específicas, possibilitando um novo olhar, muita troca, estudando com liberdade em diferentes espaços e tempo (P10).

Então, eu vejo que nas dinâmicas que eu tento construir com os alunos, não como algo pronto e acabado, mas como dinâmicas, permanentes dinâmicas; eu observo que eles me dão muitas, muitas respostas, de como eu devo proceder, que conhecimento eu posso encaminhar, como encaminhar, de que forma isso pode ser feito. Então, se fosse dizer uma base específica... Eu acho que eu sou pluri [...] Eu respiro de diferentes fontes, eu busco compreender, não que compreenda em totalidade, porque eu acho que a totalidade é inatingível (P15).

Percebe-se, nas contribuições, que os professores relatam sobre técnicas e estratégias para ensinar, citam métodos de ensino, processos de interação entre os alunos, fazem relação com os conteúdos, abordam a organização do espaço de estudo. Identifica-se, em algumas narrativas, a influência dos conhecimentos das ciências da educação, de uma maneira bastante superficial, mas que acabam sendo "incorporadas à formação profissional dos professores, fornecendo, por um lado, um arcabouço ideológico à profissão e, por outro, algumas formas de saber-fazer e algumas técnicas" (TARDIF, 2002, p. 37).

Ainda na dimensão pedagógica, foram incorporados os saberes curriculares, identificados como aqueles que estão relacionados com o conhecimento sobre o currículo e o programa escolar (objetivos, conteúdos, métodos, avaliação), "a partir dos quais a instituição escolar categoriza e apresenta os saberes sociais por ela definidos e selecionados como modelo da cultura erudita e de formação para a cultura erudita" (TARDIF, 2002, p. 38).

Dois foram os fragmentos de todos os depoimentos que mais se aproximaram dessa conceituação, porém um deles no sentido de fazer uma crítica em direção ao currículo, afirmando que "uma coisa é você abordar um conhecimento porque ele é dado como uma 
ementa, outra coisa é você apresentar um conhecimento gerado por uma necessidade, ou seja, uma problematização, problematização, no significado... Um problema em ação" (P13).

No outro depoimento, encontraram-se indícios do saber curricular, direcionados para a implementação do currículo: "[...] trabalhar de forma sistemática os conceitos de racionalidade, ciência, complexidade e humanismo nas escolas, com o objetivo de ajudar as pessoas a entender a civilização contemporânea de forma mais profunda e não superficial" (P1).

Para a dimensão epistemológica, foram considerados os saberes disciplinares e do conhecimento, no sentido de inter-relacionar os saberes para entender a organização, desenvolvimento e estudo do conhecimento científico do docente para sua atuação profissional. Na concepção de Gauthier et al. (1998, p. 30), quando se fala de saber disciplinar, "[...] não se trata de um saber disciplinar propriamente dito, mas de um saber da ação pedagógica, produzido pelo professor no contexto específico do ensino da sua disciplina", extrair o que de fato é importante ensinar daqueles saberes produzidos pelos especialistas nas áreas. Nessa mesma óptica, Tardif (2002) discorre sobre a manifestação dos saberes disciplinares a partir da tradição cultural e dos sistemas sociais que produzem esses conhecimentos.

A busca por essa essência, pelo mais significativo da disciplina para o ensino, pôde ser observada no depoimento de um participante, que apontou também a necessidade de dialogar com outras áreas/disciplinas para trabalhar a matemática financeira:

Eu sou professora de matemática. Então, o que eu precisei nesse grupo. Eu precisei de um administrador, de um economista e da professora de matemática para falar de matemática financeira; por quê? Porque a matemática financeira é ensinada já, fora do país, na Europa e nos Estados Unidos há muitos anos; ela vem sendo implementada no Brasil há pouco tempo, mas lá fora existe o que a gente chama educação financeira. Então, o que eu penso: a matemática financeira, por si só, não resolve os problemas de uma sociedade, não resolve os problemas emergentes, muitas vezes problemas que acontecem dentro da própria família. Mas, se eu falar da educação financeira aliada a uma matemática financeira, uma economia doméstica e uma administração financeira, isso possibilita que a pessoa perceba o movimento da matemática dentro desse contexto (P9).

Sobre os saberes do conhecimento, o grupo de pesquisa definiu-os como saberes adquiridos na formação inicial, continuada e em serviço que auxiliam o professor na sua profissão 
e a ter clareza sobre a importância do conhecimento no processo educativo. Essa caracterização deu-se após a compreensão de Gauthier et al. (1998, p. 31), quando fala sobre os saberes da formação profissional (das ciências da educação e da ideologia pedagógica) que são adquiridos, construídos durante a formação ou em trabalho, que "informam-no a respeito de várias facetas de seu ofício ou da educação de um modo geral", o que é complementado pela visão de Pimenta (1999, p. 22), que busca em Morin (1993) a compreensão sobre o conhecimento, esclarecendo que "não basta produzir conhecimento, mas é preciso produzir as condições de produção do conhecimento, ou seja, conhecer significa estar consciente do poder do conhecimento para a produção da vida material, social e existencial da humanidade".

Nesse sentido, identificaram-se algumas aproximações nos relatos dos professores:

Alguns autores que você estuda na faculdade e acredita que vão lhe dar uma base teórica, eles são a base dos nossos conhecimentos. Eu fui conhecendo teorias e outros estudos que foram acrescentando conhecimentos aos meus saberes (P13).

As bases científicas se fundamentam dos construtos adquiridos tanto na graduação quanto na pós-graduação. Vejo que no entrelaçamento de conhecimentos que eu adquiri na graduação, na pós-graduação, mas com esses conhecimentos, os conhecimentos adquiridos na própria prática pedagógica e das vivências do processo. Eu acredito que essas vivências estimulam o professor na busca de novos conhecimentos, não necessariamente adquiridos na graduação e na pós-graduação, e possibilitam revisitar a prática pedagógica de forma permanente (P8).

Identifica-se nos relatos o reconhecimento dos professores relacionados com a necessidade de serem construtores e reconstrutores do conhecimento e de suas aprendizagens. Isso exige do professor atualização constante e reflexão sobre sua prática pedagógica, pois não podem ficar aprisionados em verdades absolutas, uma vez que o conhecimento é transitório, de dinâmica complexa (MORIN, 2007).

Para a dimensão ontológica, consideraram-se os saberes experienciais. De acordo com Pimenta (1999, p. 20), “[...] são também aqueles que os professores produzem no seu cotidiano docente, num processo permanente de reflexão sobre sua prática, mediatizada pela de outrem - seus colegas de trabalho, os textos produzidos por outros educadores". São saberes que resultam da vivência dos docentes no ambiente acadêmico, das inter-relações estabelecidas com colegas professores e das próprias atividades profissionais. O que caracteriza esse saber é que 
sua construção se faz pela experiência relacionada ao seu papel como docente; é um saber prático, que inclui habilidades e competências para executar suas funções e especificidades do trabalho; ainda, é interativo, pois é estruturado a partir das inter-retroações com seus pares e outros profissionais.

Então isso me faz repensar na verdade, todos os dias, minha prática, porque eu penso assim: é preciso partir das problemáticas daquilo que eles estão vendo nos estágios ou na atuação em sala de aula como profissional, seja como auxiliar de classe ou estagiário remunerado (P19).

Hoje os estudantes já conseguem fazer alguma articulação daquilo que estão estudando com aquilo que vivenciam na prática, então essa percepção me possibilita perceber que o que embasa mesmo a minha prática pedagógica no ensino superior é esse olhar, essa preocupação em articular a prática - aquilo que é vivido pelos alunos e, a partir daí, desenvolver os estudos teóricos, para que seja possível a modificação dessa prática (P12).

Os diferentes saberes me possibilitam recriar, o material didático, a minha prática pedagógica, a participação dos estudantes (P8).

Essas frações dos depoimentos, apresentam alguns desdobramentos importantes no tocante a realidade que não é linear, mas circular, pois aquilo que ocorre em sala de aula pode ter reações ou outros desdobramentos imprevisíveis aos que foram planejados, retroagindo de forma informacional e permitindo que o professor repense suas ações, isto é, faça sua própria autorregulagem e auto-organização (MORIN, 2007).

\section{Considerações finais}

Nas contribuições dos professores universitários pesquisados, foi possível detectar os saberes docentes nas três dimensões definidas pelo grupo de pesquisa, a epistemológica, a ontológica e a pedagógica.

A análise permitiu identificar que na dimensão pedagógica relacionada aos saberes metodológico-didáticos, os entrevistados apontam sobre a importância da contextualização, de relacionar o estudo com as realidades sociais na possibilidade de ampliar os conhecimentos, tornando-o pertinente (MORIN, 2000), para visualizá-los na sua multidimensionalidade. Ainda nesse ponto, destaca-se a interação entre pares num processo aberto ao diálogo, a aceitação do 
outro e a capacidade de construção e reconstrução do aprendido. O aluno é visto como participante ativo e protagonista do processo, permitindo uma relação colaborativa e de respeito pela individualidade e diversidade.

Na dimensão pedagógica - saberes curriculares, percebe-se uma reflexão relacionada a superação da abordagem racionalista de estrutura classificatória dos conhecimentos, por uma visão que propicie o desenvolvimento cognitivo, emocional e, também, social dos estudantes.

Na dimensão epistemológica relacionado aos saberes disciplinares, destaca-se a busca da superação da clausura disciplinar, um convite para transcender a lógica binária e reconhecer que o diálogo e a interação com outras áreas e professores são possibilidades de emergir novas maneiras de construir conhecimentos e organizar a aprendizagem.

O saber de conhecimento da dimensão epistemológica reforça a visão de formação acadêmica e profissional, acrescentando que existe a possibilidade de traçar novos caminhos que possibilitam ao docente aprender a aprender em diferentes espaços, tempos e contextos na busca de aprendizagens que sejam autossignificativas.

Por fim, a dimensão ontológica-saberes experiencial apontada pelos participantes como aquele que se constrói pela experiência em sala de aula, com outros colegas de profissão, permeado por reflexões. Observa-se nos depoimentos que a maneira de ver, pensar e compreender a realidade permite ao professor perceber as inter-relações em substituição ao isolamento e fragmentação.

A pesquisa permitiu identificar que as tipologias dos saberes docentes de Tardif (1991, 2002), Gauthier et al. (1998) e Pimenta (1999) são bases foram pertinentes para o estudo do tema, auxiliando com fundamentos teóricos na elucidação dos saberes dos professores. Essa investigação apontou que as tipologias oferecem uma pluralidade de enfoques, mas não são suficientes para identificar que os saberes docentes são constituídos de maneira dinâmica, mutável, multidimensional, multirreferencial e não linear em sua dinâmica operacional.

Deseja-se que a pesquisa realizada com um diálogo traçado com autores que apontam os saberes docentes seja incitadora para gerar questionamentos sobre eles e fomentem um movimento para novas revelações de saberes que possam subsidiar a atuação dos professores universitários e de outros níveis de ensino. 


\section{Referências}

ANDRÉ, Marli. O que é um estudo de caso qualitativo em educação? Educação e Contemporaneidade. Revista FAEEBA, v. 22, n. 40, p. 95-104, jul. /dez. 2013.

FLICK, Uwe. Uma introdução à pesquisa qualitativa. 2. ed. Porto Alegre: Bookman, 2004.

GAUTHIER, Clermont et al. Por uma teoria da pedagogia: pesquisas contemporâneas sobre o saber docente. Ijuí: Unijuí, 1998.

KOZINETS, Robert. V.. Netnografia: Realizando pesquisa etnográfica online.1.a ed. Porto Alegre: Penso, 2014.

LUDKE, Menga; ANDRÉ, Marli. Pesquisa em educação: abordagens qualitativas. 2. ed. São Paulo: EPU, 2013.

MORIN, Edgar. Introdução ao pensamento complexo. 3ed. Porto Alegre: Sulina. 2007.

MORIN, Edgar. Toffler e Morin debatem sociedade pós-industrial. Folha de S. Paulo, World Media, 12 dez. 1993.

NÓVOA, Antonio; FINGER, Matthias (Orgs.) O método (auto) biográfico e a formação. Lisboa: Ministério da Saúde, Depart. de Recursos Humanos da Saúde/Centro de Formação e Aperfeiçoamento Profissional, 1998. p.131-153.

PIMENTA, Selma Garrido et al. A construção da didática no GT Didática: análise de seus referenciais. Revista Brasileira de Educação, Rio de Janeiro, v. 18, n. 52, p. 143-241, jan. /mar. 2013.

PIMENTA, Selma Garrido (Org.). Saberes pedagógicos e atividade docente. 1.a ed. Inserir edição. São Paulo: Cortez, 1999.

PINEAU, Gaston. Produire sa vie. 1.a ed. Paris: Edilig, 1983.

TARDIF, Maurice. Saberes docentes e formação de professores. 8. ed. Petrópolis: Vozes, 2002.

TARDIF, Maurice. Saberes profissionais dos professores e conhecimentos universitários. 1.a ed. Rio de Janeiro: PUC-Rio, 1991. 
ZEICHNER, Kenneth. M. A formação reflexiva de professores: ideias e práticas. 1.a ed. Lisboa: Educa, 1983.

Recebido em dezembro 2019.

Aprovado em abril 2020 